\title{
ANÁLISIS DEL DISCURSO DEL DEBATE SOBRE PARAMILITARISMO EN COLOMBIA APLICANDO EL SISTEMA DE MATRIZ ARGUMENTAL ${ }^{1}$
}

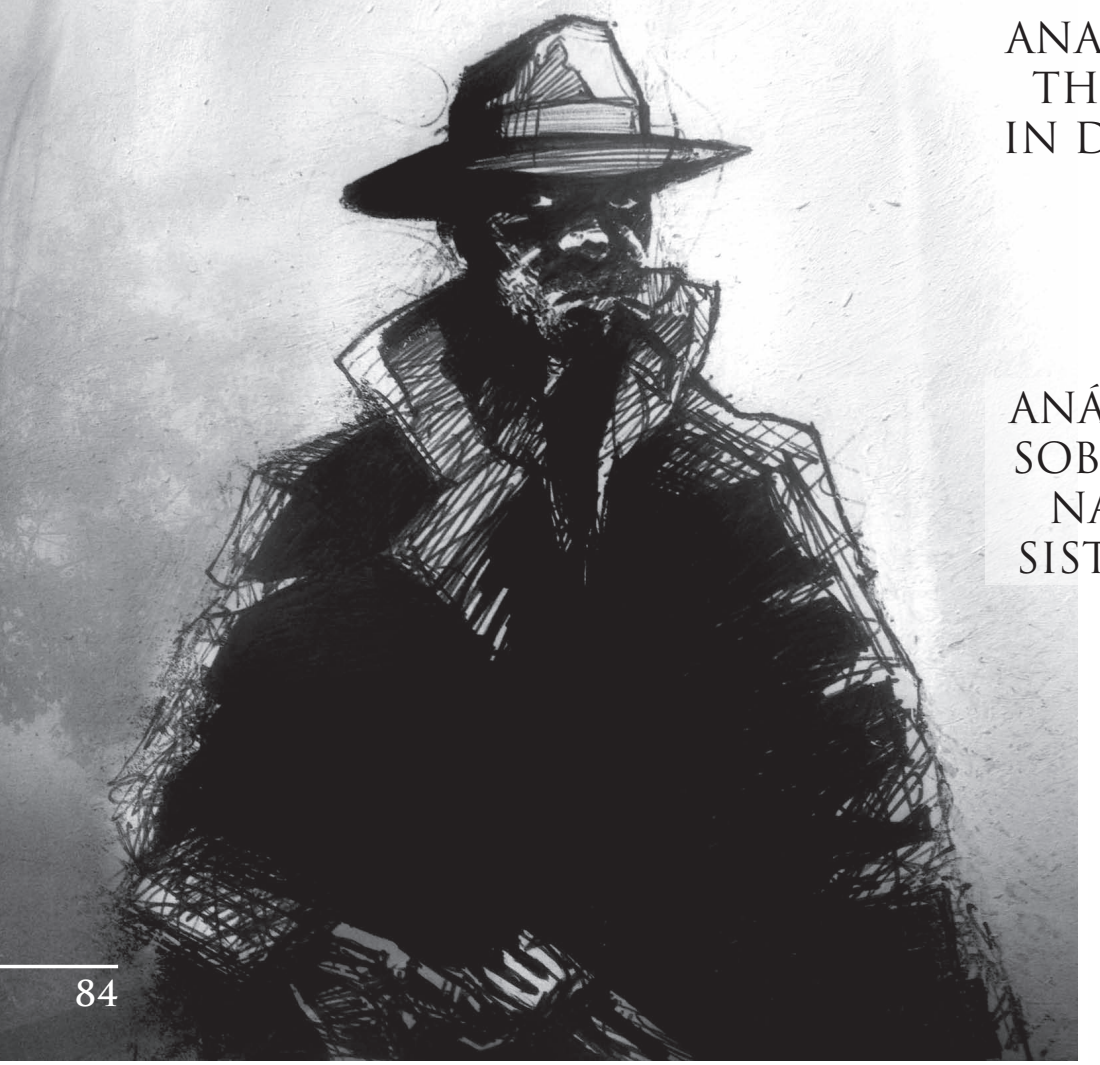

ANALYSIS OF DISCOURSE, APPLYING THE ARGUMENT MATRIX SYSTEM, IN DEBATE ABOUT PARAMILITARISM IN COLOMBIA

Por:

\section{Eliana Noscué Mera ${ }^{2}$}

Doctoranda

Universidad Nacional de La Plata (Argentina) eliananoskwe@gmail.com

Resumen: Aplicando el sistema de Matriz Argumental diseñado por el Dr. Carlos del Valle Rojas ${ }^{3}$, este artículo analiza el debate sobre paramilitarismo en Colombia realizado el 17 de septiembre de 2014. Se toma como corpus de análisis las intervenciones del senador citante, Iván Cepeda, y el senador citado, Álvaro Uribe.

El principal objetivo de la investigación es evidenciar la contundencia argumentativa de las intervenciones, por lo que verificamos la exposición de argumentos, la organización semántica y de contenido a propósito de las vastas acusaciones que le imputa el senador Cepeda a Uribe, y la defensa que este último hace en torno a dichas acusaciones. Corroboramos que la construcción discursiva del citado se compone de informaciones subjetivas, personales, familiares y en gran medida informaciones que, por omisión, desestiman la argumentación de su oponente. Para el análisis de los resultados se utilizaron principalmente los planteamientos de Teun Van Dijk, respecto del reconocimiento del discurso ideológico en su texto Ideología y Discurso (2003). 
Palabras clave: Discurso ideológico, análisis argumental, debate público, paramilitarismo, narcotráfico.

Abstract: By applying the Matrix of Arguments system designed by Dr Carlos del Valle Rojas, this article analyses the debate on paramilitarism that took place on September 17th, 2014. To this end, senator Iván Cepeda's speech and Alvaro Uribe's one are analysed. The first one was who summoned Uribe to the debate.

The main objective of this research is to show the argumentative force of the discourses. For that reason, we verified the exposition of arguments, semantic and content organization related to Cepeda's serious accusations against Uribe, as well as the defence displayed by the latter. We corroborated that Uribe's speech features subjective, personal and familiar information, which, to a great extent, by omission, neglects his counterpart's argumentation. To analyse the results, it was used the Teun Van Dijk's approach concerning the ideological discourse in his book Ideology and discourse (2003).

Keywords: Ideological discourse, analysis of arguments, public debate, paramilitarism, narcotrafficking.

Resumo: Empregando o sistema de Matriz Argumental concebido pelo Dr. Calros delValle Rojas, este artigo faz uma análise do debate sobre o fenômeno paramilitar na Colômbia, o qual teve lugar o 16 de Setembro, 2014. São estudadas as intervenções do senador que citou o debate, Iván Cepeda, e o senador citado, Álvaro Uribe.

O principal objetivo da pesquisa é mostrar a contundência argumentativa das intervenções. Por tanto, verificam-se a exposição dos argumentos, a organização semântica e de conteúdo a respeito das graves acusações do senador Cepeda contra Uribe, e a defesa do último. Confirma-se que a construção discursiva de Uribe contém em grande medida informações que, por omissão, menospreçam a argumentação do seu contrário. Para a análise dos resultados, usam-se principalmente as aproximações de Teun Van Dijk, a respeito do reconhecimento do discurso ideológico no seu livro Ideologia e discurso (2003).

Palavras-chave: Discurso ideológico, análise argumental, debate público, fenômeno paramilitar, narcotráfico. 


\section{Introducción}

Por más de 50 años, hoy Colombia es el único país latinoamericano que continúa en guerra civil. Algunos problemas sociales que se afrontan en el país provienen, directa e indirectamente, del conflicto interno armado que acontece en todo el territorio nacional entre las Fuerzas Militares, las guerrillas (FARC-EP, ELN) y los paramilitares (AUC, BACRIM) quienes ejercen el narcotráfico como fuente de ingresos. Cuando nos referimos a que algunas de las desigualdades sociales provienen de esta guerra, lo hacemos planteando que la política que se ejerce en este país ha utilizado la guerra como "cortina de humo" para culparse mutuamente sobre los conflictos sociales y políticos que suman asesinatos a líderes políticos de la oposición, desapariciones forzadas, masivos desplazamientos forzados que ubican a la nación en el segundo lugar con mayor número de desplazados migrantes internos (Centro Nacional de Memoria Histórica, 2015), gran porcentaje de pobreza, desempleo, empleo informal. La corrupción de los dirigentes políticos que se ve reflejada en firmas de licitaciones para explotación sobre territorios geográficos vitales para los pobladores, el reforzamiento del monopolio empresarial y mediático, público y privado, la privatización de la salud, la educación; en otras palabras, se ha engendrado un tipo de política "anfibia" donde sus actores actúan entre la legalidad y la ilegalidad. La "incapacidad de nuestras instituciones liberales de garantizar universalmente un mínimo de civilización política»» (Estrada Álvarez, y otros, 2015, pág. 21) ha sido un factor determinante para que diferentes grupos sociales, políticos y económicos hayan logrado transferir tendencias violentas, cínicas y políticamente incorrectas, a los estrados más altos de la dirigencia nacional.

El debate ocurrido el 17 de septiembre del 2014 sobre para-política, en contra del ex presidente y actual senador Álvaro Uribe Vélez; propuesto por el también senador Iván Cepeda, es una de las más recientes experiencias que representa, a gran escala, la situación política en Colombia. La oposición política de estos dos senadores es conocida a nivel nacional; los dos han hecho carrera en defensa de lo que para cada uno de ellos dignifica su ejercicio gubernamental. Es a partir de esa conformación ideológica desde donde se construye el nivel discursivo; nos referimos a la consideración habermasiana de la comunicación como proceso fundamental y válido para la aprehensión del mundo, de la vida, la marcada relación entre la razón y la realidad; esa realidad que es construida a partir de la interacción, de la comunicación. Así, la comprensión del mundo y el uso que se le da al lenguaje funcionan como mecanismos para posicionar la verdad, la veracidad de la realidad aprehendida (Brunner, 1997).

Iván Cepeda Castro es reconocido por su defensa a los DDHH y los procesos de reconciliación a las víctimas de la guerra. Es actual senador por el partido político del Polo Democrático Alternativo, de tendencia centro izquierda, filósofo de profesión, que desde niño se ha visto envuelto en exilios y migraciones por la persecución política a su familia. Su padre Manuel Cepeda Vargas quien fuera dirigente del Partido Comunista Colombiano fue asesinado en $1994^{4}$. 
Álvaro Uribe Vélez ha estado ejerciendo cargos públicos hace 35 años. Ha sido concejal y alcalde de la ciudad de Medellín, gobernador del departamento de Antioquia, senador de la república por dos periodos consecutivos y uno más en la actualidad; fue presidente de la república por dos periodos, siendo él quien establece en su primer mandato la reelección presidencial. Su padre Álvaro Uribe Sierra fue asesinado el 14 de junio de 1983 por un grupo de guerrilleros de las Fuerzas Armadas Revolucionarias de Colombia, FARC-EP.

En Colombia suelen ser comunes este tipo de coincidencias. Los padres de estos dos hombres fueron asesinados por grupos del conflicto armado; de hecho, sus padres y ellos mismos son actores del mismo. Podríamos suponer que las construcciones ideológicas se componen, en gran parte, de cuestiones personales que deben argumentar acciones políticas:

El entramado de convenciones preexistentes en las sociedades plantea la relevancia del bagaje cultural y potencia la descripción de la experiencia subjetiva. Es decir, se explicita el concepto más reciente de contexto, de modo que las condiciones de posibilidad de compresión y expresión de una experiencia, que sirva como descripción y narración de la realidad y del mundo, están antecedidas por significados convencionalmente establecidos y desligados de las propiedades del objeto verbalizado. (Pardo Abril, 2007, pág. 23)

Las subjetividades de estos dos actores sociales y políticos son fundamentales para la construcción de su discurso ideológico, el que argumenta sus acciones como funcionarios públicos y sus tendencias morales, éticas y profesionales. Dos posiciones, que, por ser públicas, ejercen poder de convencimiento o adhesión en la ciudadanía. "El lenguaje se configura entonces como una práctica social con dimensiones cognitivas, culturales y comunicativas, mediante el cual una comunidad ejerce poder». (Pardo Abril, 2007, pág. 21)

Unos profesan la necesidad de una guerra, que, a costa de cualquier precio, elimine la oposición, la insurgencia, y logre la recuperación del territorio nacional; esta es una de las principales insignias de la política que ejerce Uribe. Como anécdota representativa traemos a cita el tan mencionado y hostigado adjetivo de terrorista $a^{5}$ que el mandatario popularizó durante sus ocho años de presidencia, reduciendo las fuerzas insurgentes a este calificativo y negando por conexión directa el conflicto interno armado; además de calificar de colaboradores de terroristas a muchos de sus opositores políticos.

Por otro lado, otros creen en procesos de reconstrucción; reconocen el conflicto y trabajan en procesos de paz, considerando víctimas y victimarios como colombianos; además reconocen que muchas de las justificaciones de la guerra surgen de los millonarios movimientos en relación a la tenencia de tierras, el narcotráfico y el poder político que benefician tanto a guerrilleros, paramilitares y Estado. 
Lo polémico de Uribe como actor político es la tan mencionada relación con el paramilitarismo y el narcotráfico. Aunque desde su mandato presidencial surgieron distintas denuncias por dichos nexos, debido a su investidura no era posible este tipo de escenarios; fue solo asumiendo el nombramiento de senador que se facilita el espacio para la argumentación oral. Esa es la verdad que Cepeda expuso y debatió. Verdad que aun hoy, a pesar de que muchos de los colaboradores, ministros y nombrados oficiales por Uribe en sus mandatos, o están condenados, en juicios o en escapatoria, no está legitimada por parte de los entes que decretan castigos o absuelven. Como lo dice Iván Cepeda en su intervención, existen:

(...) 84 acusaciones ante la Comisión de Investigación y Acusación de la Cámara, que duermen el sueño de los justos. Existen 7 investigaciones preliminares en la Fiscalía General, lamento que no esté aquí el señor fiscal. Existe al menos una investigación preliminar ante la Corte Suprema de Justicia. Existe una querella en su contra ante el Juzgado de Instrucción Número 46 de Madrid España, por delito de encubrimiento, perdón, de descubrimiento y revelación de secretos de ciudadanos colombianos refugiados en España, periodistas españoles y asociaciones de derechos humanos de ese país. Existen 24, por lo menos hasta ahora, 24 paramilitares que han hecho distintas clases de afirmaciones que comprometerían a Álvaro Uribe en distintos momentos de su carrera política $(\ldots)^{6}$

Para hacer un pequeño contexto de lo que han sido las Autodefensas Unidas de Colombia, tendremos que aclarar que la geografía está íntimamente relacionada con los logros políticos y económicos de los grupos al margen de la ley. La zona céntrica del país, la capital y las principales ciudades funcionan con la administración estatal, dentro de un margen visible de legalidad; mientras que las fronteras, las costas y las zonas montañosas de más difícil acceso, han estado en constante disputa, durante al menos los últimos 30 años, entre paramilitares, guerrilla y Estado. En muchas de estas zonas la ley ha sido impuesta por uno de los bandos. Decía una víctima en entrevista, que no importaba quien mandara o designara la ley, si los paramilitares o los guerrilleros, lo importante era que no se encontraran, porque en ese momento ese pueblo dejaba de existir (Noscué \& Angulo, 2011).

El libro Guerras Recicladas de María Teresa Ronderos es un texto periodístico que se dedica a recorrer la historia de los paramilitares desde su nacimiento hasta los grandes logros alcanzados en la política de Colombia. A partir de su investigación, encuentra que el surgimiento de las AUC fue en Puerto Boyacá, mucho antes del "reconocimiento" de los hermanos Castaño, a quienes se les designa la creación de este grupo. Pues Fidel Castaño, quien fuera su padre ya ejercía negocios con el narcotráfico y el contrabando. Más adelante esta organización amplía sus acciones a la extorsión, el secuestro, los destierros masivos, entre otros crímenes de lesa humanidad. Funcionaban como ejércitos contraguerrilla y eran patrocinados por terratenientes que buscaban su protección. Con todo este accionar lograron expandirse a nivel nacional y tener 
capacidad de negociación con el Estado. Una historia marcada con mucha sangre que merecería un escrito propio; lo que describimos es tan solo un esbozo para que el lector perfile la situación expuesta.

Lo que nos corresponde en este momento es el análisis del discurso y los argumentos expuestos por quien cita el debate y por quien es señalado: cómo aporta cada uno a partir de su exposición y de sus argumentos, de la realidad que exponen y en la que han estado inmersos desde diferentes roles.

Desde el siglo XV hasta el XX se investigó y se le adjudicó a la industria de la comunicación e información la construcción de patriotismo, pertenencia nacional y la construcción de la agenda pública de las sociedades. Se dice que se le debe gran parte de las organizaciones democráticas y los órdenes establecidos, en relación a poderes políticos y económicos. En las últimas décadas investigadores como Van Dijk (2003) han planteado que los estudios sociales relacionados con cuestiones culturales, relaciones sociales e identidad política tendrán que ser abordados teniendo en cuenta los cambios globalizadores y el acceso a la información mediada por las nuevas tecnologías. De esta manera, los actuales debates en América Latina y en Occidente tienden a incluir "la comprensión de la naturaleza de la vida social y cultural contemporánea" (Pardo Abril, 2007, pág. 31) que está totalmente relacionada con la modificación de las formas de comunicación. Es decir que los aportes epistemológicos deben concebir las nuevas formas de relación social, que incluyen por ejemplo la ampliación de redes sociales que, si bien siempre han existido, con las digitales se transforman las interacciones sociales. Además, es necesario reflexionar también sobre las emergentes redes de comunicación que amplían las tramas sobre las posibilidades de los ciudadanos de comunicarse.

Las reflexiones y los cuestionamientos sobre las verdades impuestas deben hacer parte de los estudios sociales y ofrecer al lector las herramientas para que él mismo desvirtúe el poder establecido; de otra forma, afirmar una verdad en el plano discursivo sería legitimarse como investigador y auto-empoderarse desde el positivismo científico. Es así como creemos necesario abordar el análisis del presente corpus, teniendo en cuenta las reflexiones existentes sobre la importancia del contexto, del uso de los conceptos en un discurso y de la intencionalidad de la locución, puesto que la academia ha reconocido "la variabilidad discursiva":

Lo que las personas dicen depende del contexto particular en el que se esté hablando y de la función que cumpla en esas circunstancias; de esta manera, cuando las personas se involucran en una interacción discursiva, construyen y negocian significados, o la 'realidad' misma sobre la que están hablando. En este sentido, el análisis del discurso da cuenta de la variabilidad inherente en lo que las personas dicen. (Pardo Abril, 2007, pág. 34)

La exposición de argumentos de estos dos actores sociales no solo convoca una realidad existente, sino que genera otra construida a partir del lenguaje. Estamos frente a líneas 
de investigación que han sido claramente expuestas en la Escuela Francesa (Benveniste, Foucault) donde los aspectos psicosociales son características fundamentales para significar lo expresado. El "sujeto es simultáneamente un ser psicológico y social; así, el lenguaje no puede ser considerado como un ente independiente de quien lo produce, y está condicionado por las prácticas sociales que demarcan lo que queda expresado como implícito y lo que en efecto es explícito (...)” (Pardo Abril, 2007, pág. 49).

Por lo anterior, es pertinente asumir el análisis al corpus presentado aplicando principalmente la Matriz de Análisis Argumental. Puesto que si estamos frente a una acusación y una defensa, lo relevante de estas exposiciones es la contundencia de la argumentación. La coherencia, la cohesión, los datos presentados, la organización semántica. Por otro lado, decimos principalmente porque creemos posible interactuar con el documento y desde nuestro análisis interpretativo, desarrollar una lectura contextual de la situación:

En este sentido, lo fundamental de los ECD es la comprensión en el discurso de los conceptos de poder e ideología, mediante la apropiación de la hermenéutica, la explicitación de las estrategias discursivas, el reconocimiento de los factores contextuales en la interpretación y la adopción de un lugar político desde el cual se investiga. Además, es necesario que se reconozca que el uso de la lengua es un fenómeno social, los individuos y colectivos expresan significados y el discurso es la unidad funcional-analítica a partir de la cual el investigador da cuenta de lo que ocurre y se representa en el proceso de comunicación. (Pardo Abril, 2007, pág. 67)

A continuación, adjuntamos el formato gráfico utilizado:

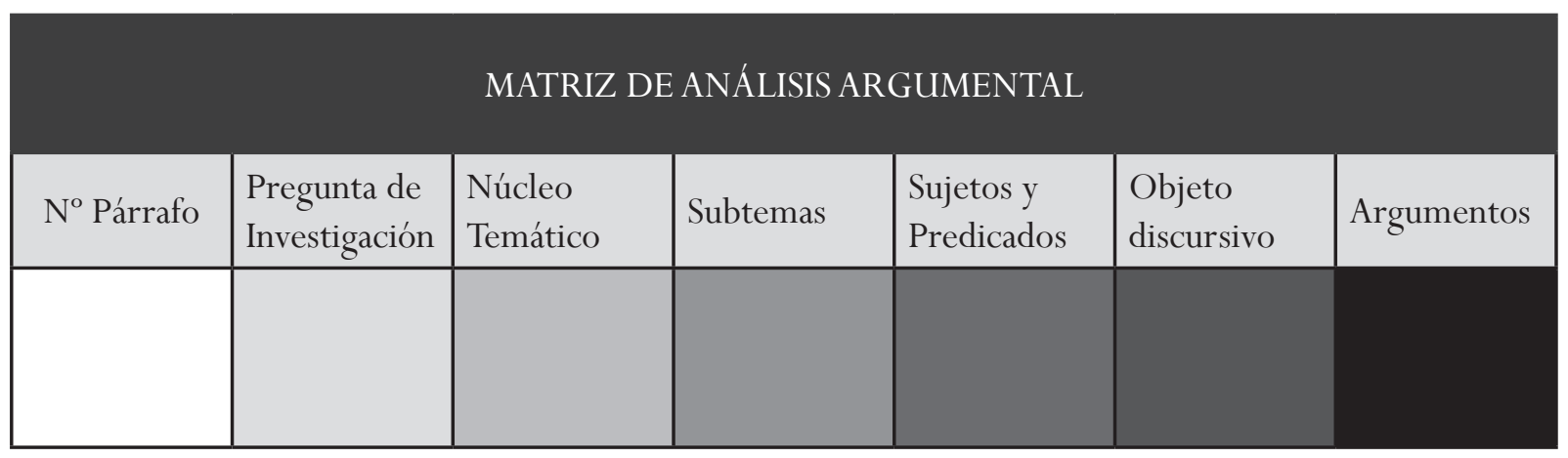

Tabla 1: Matriz Argumental

Fuente: Carlos del Valle Rojas. 
Cabe anotar que el debate se extendió por más de 8 horas, en las cuales, después de exponer el citante y el citado, expusieron otros senadores en oposición o defensa del señor Uribe. Sin embargo, el corpus se delimita a las dos principales intervenciones: la de Iván Cepeda, con una duración de 1 hora y 30 minutos aproximadamente; y la contestación de Álvaro Uribe que tiene una duración similar ${ }^{7}$. Al transcribirlas, obtuvimos un total de 45 páginas tamaño A4. 87 párrafos en la intervención de Cepeda y 100 en la de Uribe. La cantidad de estos párrafos es el resultado de la interpretación de quien transcribe el debate emitido por el Canal Institucional.

Lo que planteamos es adentrarnos en el análisis desde una división temática, basada en los cargos públicos y los correspondientes periodos desde donde Uribe construyó su carrera política. Esta escogencia se basó inicialmente en la exposición de Cepeda, quien en su discurso aborda cronológicamente estos sucesos. Para que el lector tenga una guía comparativa de la organización de los discursos del citante y el citado marcaremos cada periodo con colores distintivos que le facilitará referenciar el orden de los párrafos en el corpus.

A. Nexos familiares con el paramilitarismo y el narcotráfico

B. 1980-1982 Director de la Aeronáutica Civil

C. 1982 (agosto a diciembre) Alcalde de Medellín

D. 1986-1994 Senador por dos periodos

E. 1995-1997 Gobernador de Antioquia

F. 2002-2010: presidente de la república

Proponemos asumir la distinción de matices de negro a gris para leer dos cosas. Cepeda organiza su discurso cronológico ligado a los cargos públicos de Uribe, mientras que este último desarrolla su discurso indistintamente a este orden. Denota que muchos de esos actos de los que habla Cepeda se relacionan con las diferentes épocas de la vida pública del citado: investigaciones que siguen vigentes, casos sin concluir, testimonios y declaraciones desmentidas (notas periodísticas posteriores al debate) que decidimos no omitir en el análisis, porque a dos años del debate - de septiembre 2014 a abril 2016-, varios casos con la justicia a las que hace alusión Uribe como defensa, no le han sumado a su verdad expuesta. 
Imagen 1: Discurso Cepeda

Fuente: Elaboración propia (2016).
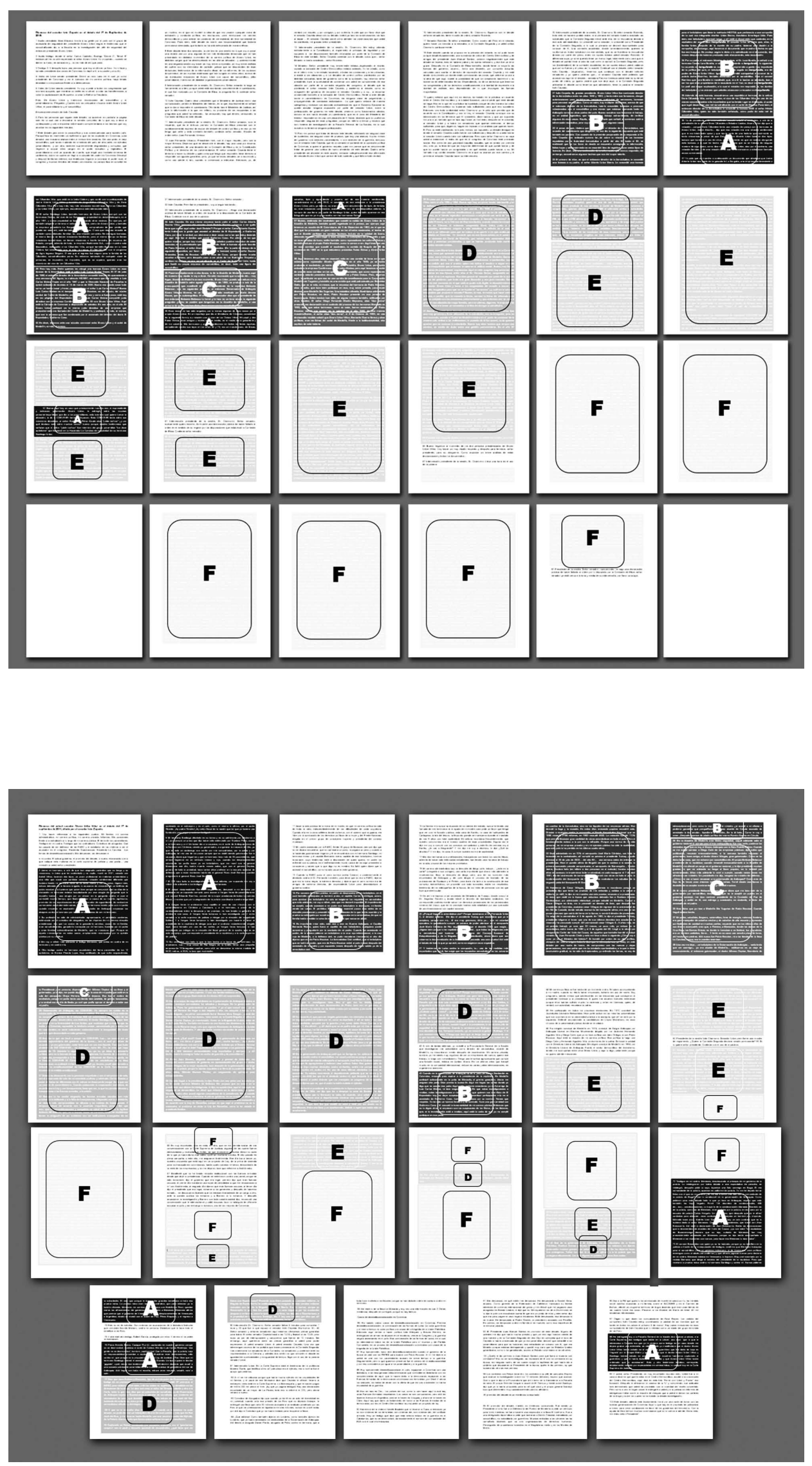

Imagen 2: Discurso Uribe

Fuente: Elaboración propia (2016). 


\section{Desarrollo del análisis Presentación Iván Cepeda}

Posterior a la presentación que hace el senador Cepeda, en los siguientes párrafos, entre el 9 y el 20, se suscitan diferentes intervenciones, entre las cuales se encuentra la del senador Jimmy Chamorro, presidente de la sesión, quien designa la palabra y regula los contenidos del debate. En ese sentido Chamorro infiere: "Señor senador, solo le recuerdo que en el Artículo primero la Comisión de Ética prescribe con el condicionamiento expreso de excluir del debate de control político y en eso yo me tengo que ceñir y esta comisión también, continúe señor senador." Es decir que el citante debe desarrollar su exposición bajo lineamientos prescritos por dicha Comisión.

Aunque en estas intervenciones se ignora al espectador nacional, pues nunca desarrollan una exposición aclaratoria sobre lo que legalmente se puede tratar o no en el debate, concluimos que Chamorro, presidente de la Comisión Segunda se ve obligado a expresar las designaciones legales que la Comisión de Ética estableció en pos de las garantías del mismo. Se infiere que está prohibido relacionar actores a actos o sucesos que no estén sentenciados o comprobados.

Como respuestas antagónicas al marco legal que expone Chamorro, están las intervenciones de Jorge Robledo, senador del Polo Democrático, un Ministro del actual gobierno y Juan Fernando Velasco, del Partido Liberal. Este último plantea que: “(...) hay una cosa por encima, señor presidente, de una decisión de la Comisión de Ética y es la Constitución Política y el derecho de los parlamentarios. El señor senador Cepeda tiene el derecho a hacer su debate y quien crea que tenga que responder, tiene derecho a responder con iguales garantías (...)”.

Por otro lado, el Ministro del Gobierno, quien se autodenomina "representante de la imparcialidad", defiende y expone las garantías democráticas que su gobierno ha dado para el desarrollo del evento. Ante esto el senador Robledo plantea que no es correcto hablar de garantías, puesto que:

Este debate cuando se propuso en la plenaria del Senado, no se pudo hacer porque desafortunadamente, una sumatoria de votos del Centro Democrático y de amigos del presidente Juan Manuel Santos, votaron negativamente que este debate se hiciera; esto es historia patria y es bueno señalarlo; y ese fue un error grave. Después en la Comisión de Ética también, donde tiene la mayoría las fuerzas del gobierno, asume... toma una decisión, por completo absurda; calculada para coartar el derecho de expresión del senador Cepeda y me está dando la impresión por donde están comenzando las cosas, que usted se va unir a la idea de que aquí, existe la posibilidad de que los senadores hablemos o no hablemos de determinados temas. Dependiendo, no de los derechos que tenemos los congresistas y de los derechos constitucionales a la libertad de expresión a la libertad de análisis; sino dependiendo de lo que impongan las fuerzas mayoritarias. ${ }^{10}$ 
Abordando este suceso, y teniendo en cuenta que lo hacemos desde una posición interpretativa, en relación a los actores y a lo que ellos y sus discursos significan, concordamos que "como sostiene James Farr, «Los actores, al actuar políticamente, hacen cosas por motivos estratégicos y partidistas en y a través del lenguaje; y pueden hacer esas cosas porque en el lenguaje los conceptos constituyen, parcialmente, creencias, acciones y prácticas políticas»”. (Del Valle \& Torres, 2014, pág. 39) En consecuencia, aunque esta distorsión inicial, adrede o no, pone en duda la legitimidad de la información que va a exponer el senador Cepeda, sus defensores, arduos hacedores de la palabra, legitiman su derecho parlamentario y de la Constitución Nacional de expresarse. En otras palabras, legitiman el debate a partir de los “usos de la argumentación”.

\section{Presentación de Álvaro Uribe Vélez}

A partir del capítulo 2 y hasta el 17, el senador citado hace un recuento personal sobre su familia. Se refiere a las profesiones de sus padres, sus hermanos y hermana, a la conformación de sus familias y sus desempeños comerciales. También menciona cómo incursiona en el mundo político gracias a su madre y relata el día de la muerte de su padre a manos de las FARC-EP. Hace rápidas referencias sobre los casos que vinculan a sus hermanos con propiedades delictivas. No podríamos pedir objetividad en temas tan subjetivos como la familia, así que tomaremos los párrafos que, a nuestro parecer, aportan a la relación política de la familia Uribe y los nexos expuestos y argumentados por Cepeda. Nos adentraremos a estudiar una verdad que no está legitimada por el Estado colombiano:

Pareciera que una voluntad de verdad se reafirma en la creencia de que ella no tendría ninguna relación con el poder, pareciera que esta verdad que nos sujeta, no tendría nada de subjetivo, en fin, pareciera que estamos condenados a estas pretendidas verdades objetivas. La verdad funciona de manera eficaz ocultando el ejercicio de poder en el que se constituye, siendo que en el ejercicio de un poder se configuran saberes que posibilitan que ciertos enunciados funcionen como verdaderos y así se constituyan objetos y sujetos, a partir y a través de un poder/saber.

(Del Valle \& Torres, 2014, pág. 74)

Nexos familiares con el paramilitarismo y el narcotráfico

\section{Relación sentimental/comercial de Jaime Alberto Uribe con Doris Cifuentes.}

Por un lado, la matriz logra develar que en el párrafo $2^{11}$, Uribe nombra subtemas, sujetos y predicados que finalmente no desarrolla en los argumentos. Por el contrario, el citante cumple con los contenidos que presenta inicialmente en el párrafo 26, contra-argumentando la posición de Uribe sobre el desconocimiento de dicha relación, 
exponiendo que hay dos hijos procreados a partir de la misma. Posteriormente en el párrafo 27 Cepeda continúa ampliando que la relación se extiende al campo comercial, presentando como prueba un documento legal que hace referencia a la misma. Ante esto el citado no hace mención.

\section{Santiago Uribe: su relación con los paramilitares y los narcotraficantes.}

En esta cuestión temática, donde se debate la relación de Santiago Uribe con el paramilitarismo, encontramos que en los párrafos 28, 36 y 51 Cepeda expone diferentes situaciones de dicha vinculación. Podemos decir que en los párrafos $28 \mathrm{y}$ $36^{12}$ su exposición cumple con un orden semántico, desarrolla los temas que enuncia, expone con claridad los sujetos y sus acciones y, finalmente en sus argumentos, presenta documentos, fechas, nombres completos, cifras e incluso un testimonio de Uribe donde acepta la relación de amistad con la familia Ochoa; es evidente que Cepeda utiliza esta herramienta para argumentar que dicha relación no hacía parte de la amistad solamente. Ya en el párrafo 51 el citante desarrolla una argumentación en cadena, con el fin de afirmar una relación de Santiago Uribe con el paramilitarismo; es decir comienza con un sujeto: Álvaro Uribe, que siendo gobernador emite una licencia de funcionamiento a una Convivir, con miembros paramilitares, que tenían su funcionamiento en una finca de Santiago Uribe. Hace hincapié en acciones puntuales para argumentar la relación intrínseca que ya conocemos.

Por otro lado, tenemos la defensa de Álvaro Uribe respecto de su relación y la de su hermano Santiago con el narcotráfico y el paramilitarismo. En general, el discurso no cumple con el orden semántico. En muchas ocasiones presenta subtemas que no desarrolla en su argumentación, en otras presenta sujetos sin predicado, sin acción. En otros momentos omite la contextualización de alguna información. Es como si diera por sentado que el espectador conoce el contexto de lo que habla. Por ejemplo, los párrafos 4, 7 y 10 carecen de argumentación. Hace exposición sobre temas relacionados con la justicia y su hermano, pero nunca expone cuestiones puntuales sobre como "el CTI aclaró la infamia", o sobre como la venta de una finca logró arruinar a Santiago y acabar con su honra" (Uribe). En el párrafo 4 nombra al testigo Meneses, pero solo para aclarar que hablará de él más adelante. Lo hace en el párrafo 73 , expone 6 argumentos que no terminan de aclarar que aportó o no el testigo Meneses en contra de su hermano y de él.

\section{0-1982 Director de la Aeronáutica Civil}

Afortunadamente para nuestra labor de análisis, la construcción de estos párrafos coincide temáticamente, permitiéndonos comparar los argumentos que los dos parlamentarios presentan sobre los mismos sucesos, datos o anécdotas. En primera instancia abordaremos la presentación que Cepeda desarrolla a propósito de las funciones que tenía Uribe siendo Director de la Aeronáutica Civil, en los párrafos $21^{13} \mathrm{y}$ $22^{14}$. En ese sentido expone el proceso de solicitud y la respuesta dada por esa entidad 
en relación a la documentación sobre licencias de aviación otorgadas en el periodo de 1980 y 1982. Su argumento principal es que dicho folio carece de hojas que han sido extraídas. En respuesta, el citado, en el párrafo 20 dice: "ahora dicen que nos robamos la documentación de la Aeronáutica, ¡necesito una sola prueba! Ahí está el listado de todo lo que yo aprobé, como se exigieron esos requisitos".

La respuesta de Uribe no se corresponde con la información expuesta por Cepeda. En cuanto a los sujetos, el citante nunca lo nombra como responsable de la desaparición de algunas hojas; sin embargo, Uribe asume ser ese sujeto, aunque desde la negación. Posteriormente asevera que está toda la documentación de su periodo, sin atender que su antecesor ha presentado un documento donde el actual director de la Aeronáutica certifica que no es así.

Cepeda en su exposición antecede que tratará sobre algunas de las licitaciones más polémicas que su equipo investigativo ha indagado. Comienza con la licencia dada a un helicóptero propiedad del señor Alberto Uribe Sierra que tiempo después, según la exposición, es encontrada en Tranquilandia, territorio de narcotraficantes. Así, en el párrafo $23^{15}$ presenta como argumento un documento que desmiente el testimonio de la familia Uribe respecto del destino final del aparato. En este párrafo, quien cita se antecede al planteamiento que Uribe hace en relación con este suceso. Posteriormente en el párrafo 24 expone dos testimonios de miembros del Estado (Ministro y Coronel) que estuvieron en la diligencia de allanamiento y nombran directamente al padre de Uribe como propietario del helicóptero.

Ante esto, en los párrafos 14 y 15, Uribe presenta diferentes argumentos respecto de la situación. El primero es que él no fue quien concedió la licencia porque se declaró impedido; sin embargo, no nombra ningún documento que compruebe lo que dice. El segundo argumento se refiere al suceso que ya nombró Cepeda; y plantea que el periódico ElTiempo hizo todas las averiguaciones, y con documentos de la Aeronáutica, comprobaron que su familia había vendido el aparato y que el helicóptero que se encontró en poder de Pablo Escobar, no era el mismo; sin embargo, tampoco muestra ningún documento referencial.

En el párrafo 25 el citante, con número de licencia, saca a relucir el otorgamiento a los Cifuentes Villa, reconocidos narcotraficantes; ante esto podemos rescatar que en el párrafo 20 Uribe dice: "que todas las diligencias ante la aeronáutica civil tuvieran el visto bueno del Consejo Nacional de Estupefacientes y de la Brigada Militar de Jurisdicción”. Entendemos que, si los procedimientos fueron de esta manera, no cumplieron con su objetivo, porque existen licencias a personajes condenados y relacionados con el narcotráfico. Por lo demás, Uribe no hace ninguna otra referencia respecto de esta licencia. Por el contrario, en los párrafos 21 y 22 resalta todos los logros y gestiones que realizó en su cargo.

Por su parte, en el párrafo 29, Cepeda se refiere a la junta directiva que, según él, compartieron Luis Carlos Molina y Uribe. Es comprobado que Molina hizo parte de 
los carteles de Medellín y el Norte del Valle. Como prueba, pone a disposición un documento legal (la Cámara de Comercio) que certifica que Uribe hizo parte de la junta directiva de Confirmeza S.A. En pro de relacionar este suceso del pasado con uno presente, Cepeda nombra un titular del periódico El Espectador (de ese mismo día) donde vinculan el asesinato de Guillermo Cano, antiguo director del periódico, con la gente de Molina. Es evidente que, aunque no hace una referencia directa, pretende relacionar a Uribe con estas acciones.

Como respuesta directa, encontramos que en el párrafo $43^{16}$ expuesto por Uribe, se contra-argumenta con otro documento; una carta firmada por él donde rechaza la invitación a formar parte de esa junta directiva. Además, llamando al respeto que se le debe dar, prioriza sobre una relación de amistad íntima que tuvo con Guillermo Cano. Para efectos del análisis creemos que un documento legal desestima en gran medida un documento personal; es decir que una carta personal se puede hacer indistintamente, sin un reconocimiento legítimo, mientras que un documento emitido por una jurisdicción publica transciende lo personal y certifica las acciones públicas de un individuo.

Por otro lado, y aunque nos salimos de los testimonios expuestos directamente en el corpus, encontramos que días después del debate fue entrevistada la esposa de Guillermo Cano, respecto de la amistad de Uribe con su esposo fallecido: "Ana María Busquets de Cano desmintió las afirmaciones hechas por el ex presidente durante el debate del pasado miércoles en el Congreso: ser amigo no creo, por lo menos en mi casa nunca estuvo, ni yo conocí que hubiera esa amistad en ningún momento, dijo Busquets a Noticias Uno"17.

\section{Alcalde de Medellín}

Manifestamos que una constante en la argumentación del discurso de Uribe son los relatos y anécdotas en primera persona y construidas a partir de frases subjetivas, familiares y poco formales, teniendo en cuenta el contexto del suceso; por ejemplo: “¿Cómo me vas a hacer renunciar a la gobernación de Antioquia? Como eres de flojo tú, te llevan unos chismes míos y me echas. Tomé desde esa época la decisión de no aceptar nombramientos, y rechacé muchos”, “... no obstante el dolor del asesinato de mi padre”, “... lo que necesito es un hacker en mi corazón, para que me ayude a meterme en los corazones de mis compatriotas, que los quiero" ${ }^{18}$.

Ante el suceso puntual y polémico sobre la salida de Uribe de la Alcaldía de Medellín en tan poco tiempo, Cepeda en los párrafos $35^{19}$ y $37^{20}$, apoya su argumento trayendo a colación un fragmento de un libro que contiene el testimonio del gobernador del momento Álvaro Villegas Moreno. Para reforzar su testimonio enfocado en demostrar la relación de la familia Uribe con gente del narcotráfico, muestra una nota periodística de la época que habla sobre dichas relaciones. Finalmente, en el párrafo 38 refuerza su exposición con una publicidad que evidencia la presencia del padre de Uribe en corridas de toros, organizadas por Pablo Escobar. Ante estos argumentos, 
el citado responde y hace referencia desde descripciones subjetivas y omisiones a los argumentos presentados por el citante.

Resaltamos que en el análisis específico de Uribe encontramos una incongruencia de contenido (párrafos 24 y 25) relacionada con el valor de la palabra, que él tanto replica, pero que vemos no se cumple incluso en el mismo discurso y en dos párrafos seguidos:

"El propio Belisario Betancur presidente de la república, cuando renuncié irrevocablemente a la Alcaldía de Medellín, me ofreció un cargo en el gobierno nacional, y le dije: presidente muchas gracias; lo que en adelante no tenga el favor popular, no lo recibiré por nombramiento. Años más adelante lo volví a cumplir, cuando varias veces me ofrecieron ser ministro".

"El mismo presidente Belisario Betancur, que dicen que me hizo salir de la gobernación por narcotráfico, después de que no le acepté un puesto en el gobierno nacional, me hizo nombrar presidente de la Comisión de Paz de Antioquia; y actúe en él, con entrega y convicción, no obstante, el dolor del asesinato de mi padre".

En el párrafo de arriba asevera no haber aceptado cargos por nombramiento, asegura que lo cumplió incluso años más adelante; pero en el párrafo siguiente informa que fue nombrado en un cargo en el que actuó con entrega y convicción. Creemos este momento específico como una equivocación fundamental para la significación que el citado pretende darle a su exposición: "Desde esta mirada será posible desarrollar una forma de análisis conceptual de las ideologías cuyo énfasis no sea la búsqueda de una verdad, sino la indagación del carácter aporético de los lenguajes políticos y la complejidad de los modos en que son usados para legitimar la acción política”. (Del Valle \& Torres, 2014, p. 49) Porque nuestra finalidad analítica se enfoca en la contundencia argumentativa, más allá de reivindicar una verdad, exponemos su contundencia:

Una ideología, entonces, no es necesariamente 'falsa': en cuanto a su contenido positivo puede ser 'cierta', bastante precisa, puesto que lo que realmente importa, nos dice Žižek, «No es el contenido afirmado como tal, sino el modo como este contenido se relaciona con la posición subjetiva supuesta por su propio proceso de enunciación». Estamos dentro del espacio ideológico en sentido estricto desde el momento en que este contenido - 'verdadero' o 'falso' (si es verdadero mucho mejor para el efecto ideológico) - es funcional respecto de alguna relación de dominación social de un modo no transparente. (Del Valle \& Torres, 2014, págs. 36-37) 


\section{6-1994 Senador por dos periodos consecutivos.}

En este punto, la temática central sobre la que expone el citante, es la participación de Uribe en la reforma constitucional que pretendía incorporar la extradición de los narcotraficantes. En general, esta temática carece de argumentos contundentes, tanto en documentos como en referencias puntuales de este momento histórico. Los dos exponen desde anécdotas o experiencias personales que, a nuestro modo de ver, responden a sus interpretaciones personales pero no demuestran mayor responsabilidad en la situación. Los argumentos o conclusiones hacen parte de sus interpretaciones. Se sigue percibiendo que en la organización de la exposición los párrafos de Cepeda están mejor desarrollados, en tanto Uribe continúa exponiendo temas y sujetos que posteriormente no desarrolla, para finalmente dejar a sus intérpretes o espectadores un poco confundidos con los sucesos que expone:

“¿y cuál es la solución imaginativa que propone el senador? Bueno, ni más ni menos que hacer coincidir la fecha, o perdón, que no coincida la fecha, cambiar la fecha del referendo para que no coincida con las elecciones parlamentarias y que entonces eso no vaya a generar una situación de mayor tensión; pero en ultimas, digamos, la propuesta de Álvaro Uribe era lanzar un salvavidas a la idea de derogar la extradición" (Cepeda).

"Lo que yo propuse - Por eso preguntó el periódico ElTiempo y lo encontró en la historia de este congreso- es que si se iba a aprobar el referendo para que los colombianos dijeran si aprobaban o no la extradición, tenía que ser en una fecha diferente a los procesos electorales, para que no hubiera presiones de bandidos, sobre la clase política. Esa fue mi propuesta. Nunca participé en la elección de la constituyente" (Uribe).

El argumento más puntual que encontramos en la exposición del citante es el relato sobre el proceso que lleva a cabo el FBI sobre los dineros que el narcotráfico entregó a la campaña del citado; sin embargo, extrañamos, ante lo contundente de dicha información y teniendo en cuenta las características de sus argumentos, que no exponga un documento legal que lo apoye.

\section{5-1997 Gobernador de Antioquia.}

En este punto decidimos unir en la matriz algunos párrafos que a nuestro parecer tienen una relación entre los argumentos que se exponen. Es interesante ver cómo el citante desarrolla una argumentación en cadena que comienza con las declaraciones de paramilitares sobre la híbrida relación entre el paramilitarismo y las Convivir, para pasar luego a exponer sobre las finalidades institucionales apoyadas por Uribe, y las 
que, según Cepeda, hacían parte de la creación de una fuerza ilegal, dotada de armas y de poder político. Posteriormente, relaciona los objetivos que alcanzaron las Convivir y los paramilitares para demostrar como efecto de esta alianza y este reforzamiento el incremento de violencia, especialmente en el Departamento de Antioquia, que era gobernado en ese momento por Uribe. Es muy bien pensado el desarrollo semántico de esta argumentación. Gracias a su distribución temática a lo largo de los párrafos, queda como contexto que todo esto ocurrió bajo el mandato departamental del citado.

Aunque ya lo hemos planteado, insistimos que el discurso de Uribe tiende a la falta de contextualización. Recae constantemente en nombrar personas, situaciones y anécdotas que son difícilmente comprendidas en nuestro análisis. En esta etapa, fue solo en los párrafos iníciales (del 29 al 32) donde defiende su postura frente a las Convivir. Expone argumentos relacionados con un estudio de la Universidad de Los Andes y relaciona este hecho con su tesis de cooperación Fuerzas Armadas/ Ciudadanía. Los párrafos subsiguientes son relatos en primera persona: experiencias y anécdotas que no son apoyadas por documentos $\mathrm{u}$ otras fuentes argumentativas que sustente su discurso. Fue complejo para nosotros categorizar algunos párrafos en la matriz por lo inconcluso de los contenidos.

Incluso en los párrafos $33^{21}$ y $34^{22}$ trata de desarrollar una contextualización sobre su relación con los altos mandos militares (algunos de los cuales se encuentran hoy en día en procesos o condenas) y el desconocimiento de acciones ilícitas o la solicitud personal de inclusión a sus anillos de seguridad durante la Gobernación. Como información periodística extra-corpus encontrada en el desarrollo de nuestro análisis, traemos a colación una nota publicada días después del debate, donde el General Herrera Berbel, desmiente la anécdota expuesta por Uribe en el párrafo 34:

En una carta, el mayor general (r.) Eduardo Antonio Herrera Berbel señaló que las afirmaciones del ex presidente y hoy senador Álvaro Uribe carecen de "razón y verdad", por lo que le pidió rectificarse.

En su intervención en el polémico debate del miércoles en el Congreso, Uribe dijo que asistió a un homenaje en el Hotel Tequendama rendido a los generales Fernando Millán y Rito Alejo Del Río por una invitación del general Herrera Berbel, quien actualmente es el rector de la Universidad Militar Nueva Granada.

El oficial en retiro negó que haya realizado esa invitación, y aseguró que, para esa época, 29 de abril de 1999, él era el comandante de la Cuarta Brigada del Ejército y le "estaba vedado intervenir, a cualquier título, en asuntos de carácter político”. 
Añadió que él no organizó ni participó de ese homenaje, y que, por eso, "en sana lógica", no lo pudo haber invitado. "Para refutarlo con mayor acento, me permito citar al periodista Paco Gómez Nadal, quien en una de sus columnas dio cuenta a la opinión que uno de los organizadores del mencionado evento fue precisamente 'el entonces ex gobernador de Antioquia y candidato presidencial Álvaro Uribe Vélez'_,, manifestó el general Herrera Berbel ${ }^{23}$.

Finalmente nos referimos a la prueba de comunicaciones entre paramilitares y Uribe, que se encuentra en un cable de Wiki Leaks, por medio de beepers (aparatos de comunicación que en Colombia estuvieron en auge en los años 90), la cual es presentada en un debate pasado por el ex congresista Gustavo Petro y que es traída a colación por el citante en los párrafos 46 y 47. Ante esto, la respuesta dada por Uribe en el párrafo $64^{24}$ se limita a plantear que en su periodo de gobernación NUNCA utilizó beeper. Se nos hace difícil imaginar una gestión política que no utilice los aparatos tecnológicos de comunicación que están siendo utilizados a nivel nacional, incluso por personas del común, y que un gobernador departamental asevere que nunca lo utilizó. De esta manera desmiente al paramilitar que asegura que se comunicaba por beeper; sin embargo, seguidamente, en el párrafo $65^{25}$ cita a otro paramilitar que declara sobre otra situación, y en el segundo caso que lo favorece, legitima el testimonio. Es decir, que, ante la palabra de dos paramilitares, individuos con perfiles éticos y morales similares, Uribe legitima y deslegitima la información de acuerdo a su conveniencia testimonial.

\section{2-2010: presidente de la república}

Nos remitiremos puntualmente a la pregunta de investigación sobre la relación de Uribe con Enilce López en el párrafo $74^{26}$ por parte de Cepeda y el $52^{27}$ por parte de Uribe. Respecto de esta información Uribe acepta que su primera campaña presidencial recibió dineros de una empresaria que actualmente cumple condena por lavado de activos y otras relaciones con el narcotráfico y el paramilitarismo. Es compleja esta aceptación si la vinculamos primero con la información de orden histórico que como colombianos conocemos, y es que durante el primer mandato presidencial se negó esta relación y solo se aceptó cuando se proyectaba la reelección.

Relacionando la aceptación que hace el citado respecto del apoyo económico de Enilce López, vemos contradictorio cómo en el mismo párrafo, y como lo había hecho ya en ocasiones pasadas, menciona un adjetivo que él expone como calificativo para su familia, para su persona y en este caso para su gestión política, LA AUSTERIDAD. Significado que se relaciona, entre otras actitudes y aptitudes, con la rigurosidad en el cumplimiento de las normas morales, legales, éticas; en ese sentido sería poco austero recibir apoyo económico de quien se conoce o sospecha está inmerso en negocios ilícitos. 
Recordemos que Uribe permite y lidera la visita al Congreso Nacional por parte de tres paramilitares. Nos referimos a "Ernesto Báez", Salvatore Mancuso y Ramón Isaza. En el párrafo 75 Uribe hace mención del suceso; sin embargo, nos llama la atención que ante las constantes menciones de austeridad haya propiciado un suceso histórico que se inscribió en la memoria nacional con indignación, por la disparidad tan significativa entre las características de un lugar como el recinto de la justicia, que recibe en el marco de la honorabilidad (el proceso de Justicia y Paz) a personajes que abanderaban un nivel de violencia como lo hacían estos tres sujetos.

Aunque la visita fue hecha por tres líderes paramilitares, el citante solo hace mención de Báez, suponemos que es porque trae a colación su testimonio como argumento central de la responsabilidad de Uribe en este suceso. Como contraargumento a esta denuncia, Uribe hace hincapié y califica la información como infamia, sin embargo expone como argumento el testimonio de Luis Carlos Restrepo, uno de los implicados. Aunque los dos argumentos son similares en cuanto a la generalidad de la información, el de Cepeda, por ser el del testigo directo, puede llegar a ser más contundente que el del segundo implicado, como lo es Luis Carlos Restrepo, quien también se defiende de la acusación.

En los párrafos $55^{28}$ y $58^{29}$ se evidencia la herramienta de subjetivación utilizada por el senador. En el párrafo 55 asume hablar de las acusaciones que se le hacen a su gobierno por obstaculizar las investigaciones del paramilitarismo; sin embargo, después de nombrar la temática se desplaza a hablar de un caso de injusticia cometido contra el senador Luis Fernando Velasco durante estos procesos. Difícilmente se comprende de qué habla, puesto que enfoca su discurso a situaciones personales de su relación con el señor Velasco.

En el párrafo 58 tuvimos, incluso, problemas para reconocer un objeto discursivo ante una descripción romántica de su amor por sus compatriotas. Cierra el párrafo diciendo "Pero ese tema también está en la justicia"; lastimosamente para su contundencia argumentativa, en la actualidad el hacker del cual habla tan desinteresadamente, ya se encuentra condenado ${ }^{30}$.

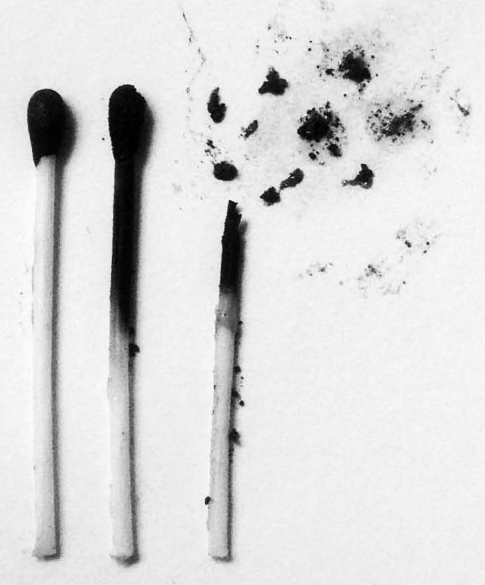

Por otro lado, respecto a la relación paramilitar del citado, específicamente con Salvatore Mancuso, Cepeda expone en el párrafo $69^{31}$ una declaración de Mancuso en que se refiere al apoyo que obtuvo en la campaña presidencial de los paramilitares. Ante esto, en el párrafo $61^{32}$, Uribe niega estas relaciones y habla sobre una declaración de Mancuso donde niega el apoyo a las presidenciales. A diferencia del citante, y como hemos visto en el transcurso del corpus, no entrega datos precisos sobre la declaración; además, existe una contradicción sobre si conoció o no a Mancuso. 
Ante su defensa de la aplicación de la Ley de Extradición - "Y la apliqué sin contemplaciones como presidente. Hay alrededor de 1.200 casos de extradición.

Desmonté los paramilitares"- exponemos nuestro análisis político: recientemente, por ejemplo, Estados Unidos condenó a Salvatore Mancuso a 15 años de prisión. Si se tiene en cuenta los crímenes que cometió siendo líder paramilitar, creemos que ser castigado por otro país, por un crimen como el del narcotráfico, es simultáneamente eximirlo de los crímenes de lesa humanidad que cometió en Colombia, y por los que no será juzgado ${ }^{33}$.

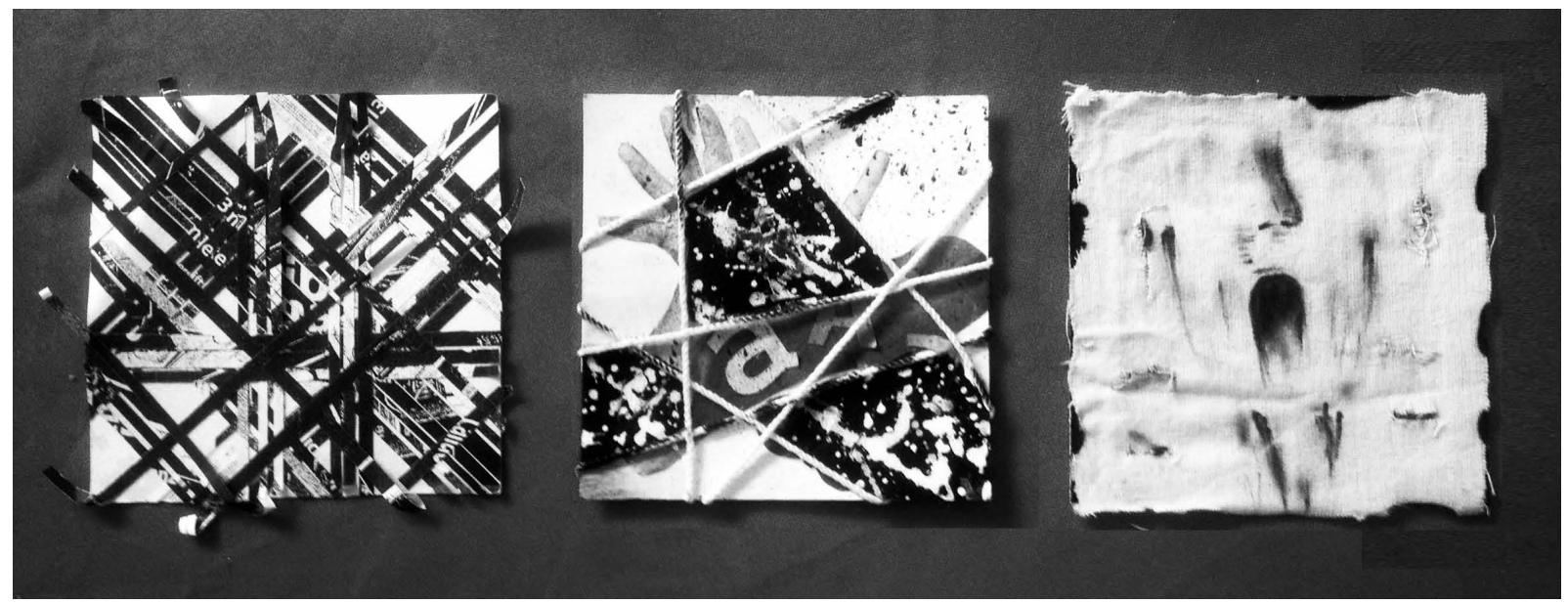

\section{Conclusiones}

Cuando asumimos analizar el corpus presentado, lo hicimos a partir de dos premisas: la primera bajo la hipótesis de que el discurso de Álvaro Uribe Vélez, elaborado para el debate de septiembre 2014 en el Congreso Nacional de Colombia, es un discurso ideológico; y la segunda, que a partir de la utilización de la Matriz de Análisis Argumentativo, conoceríamos la contundencia en la exposición de argumentos, respecto de las vastas acusaciones que le imputa el senador organizador del debate, Iván Cepeda.

En primera instancia, si tomamos como base analítica algunas características presentadas por Van Dijk (2003) encontramos que gran parte de la construcción discursiva de Uribe se compone de informaciones subjetivas, personales, familiares y en gran medida informaciones que desestiman la argumentación de su oponente, por omisión:

"Las representaciones sociales son propias de los grupos, en la medida en que son compartidas por (las mentes de) los miembros de grupos sociales (Farr y Moscovici, 1984). Esto significa que es necesario disminuir la distancia entre estas cogniciones sociales y las cogniciones personales (tales como el conocimiento y las experiencias personales) que subyacen al texto y al habla individuales. A través de otras representaciones sociales, como el conocimiento y las actitudes socioculturales, las ideologías influyen también en el conocimiento específico y en las creencias de los individuos usuarios del lenguaje. 
Estas cogniciones personales representadas en modelos mentales de acontecimientos y situaciones concretos (incluyendo situaciones comunicativas), controlan a su vez al discurso, por ejemplo, en el recuento de experiencias personales, o en la argumentación alrededor de las opiniones personales (Van Dijk, 2003, pág. 19)

Como características encontradas, están la categorización que Van Dijk hace respecto de la descripción y atribución de acciones positivas del grupo de pertenencia (ingroup) y los grupos ajenos (outgroup). En este sentido, cuando Uribe se describe a él y a sus relaciones se puede reconocer fácilmente que hace uso de énfasis, aserción, hipérboles etc. y cuando se refiere a todos y a todo aquello que está por fuera de su grupo de pertenencia, hace uso de la denegación, subestimación, de-topicalización, marginación etc.

Cabe anotar que iniciamos las conclusiones determinando el discurso de Álvaro Uribe Vélez como ideológico solo para anteceder lo que pudimos constatar utilizando la Matriz de Análisis Argumental. Su discurso es complejo y, debido a su contenido aporístico, no se ubica fácilmente en la Matriz utilizada; a partir de ello, encontramos que los argumentos presentados carecen de contundencia, informaciones explicitas referente a fechas, nombres, contextos históricos detallados y documentos sobre su defensa.

En cuanto a la composición gramatical, fue complejo ubicar desde los párrafos de su discurso el núcleo temático, el objeto discursivo y los subtemas; esto debido a que normalmente enuncia varias temáticas en un mismo párrafo, que al final no desarrolla en los argumentos presentados. Con respecto a los sujetos y los predicados, por lo general o nombra sujetos que realizan acciones que no puntualiza, o nombra acciones donde difícilmente, por la vaguedad de la información, sabemos quién actuó.

En concordancia con lo que pretende en su discurso, debemos decir que apela en todo momento a su inocencia respecto a lo que se le imputa. Normalmente hace hincapié en los valores morales y éticos que ejerce en sus gestiones políticas, personales, comerciales, y expone su conocimiento y forma de asumir la gestión política como la adecuada para gobernar el país.

Haciendo referencia al discurso de Iván Cepeda, creemos que es evidente su intención y su preparación sobre la información que presenta. Pocas veces utiliza frases o información alejada de sus 
objetivos. El discurso de Iván Cepeda se ubica fácilmente dentro de las categorías de Matriz Argumental, pues desarrolla en sus argumentos los temas enunciados al inicio, puntualiza sobre datos, nombres y fechas; además, presenta los sujetos con los predicados o acciones. Asimismo, muchos de los argumentos presentados se concluyen en pruebas documentales: documentos legales y testimonios periodísticos escritos y audiovisuales.

Finalmente, aseverar que contestamos a la pregunta de si Uribe está implicado con el paramilitarismo y el narcotráfico, es suponer tener una verdad. Lo que si concluimos es que la composición de su discurso carece de contundencia argumentativa.

\section{Notas}

${ }^{1}$ El presente artículo es el resultado de labores investigativas desarrolladas en el Centro de Investigación y Desarrollo en Medios, Industrias Culturales y Televisión, adscrito a la Facultad de Comunicación Social y Periodismo de la Universidad Nacional de La Plata.

${ }^{2}$ Licenciada en Literatura, Comunicadora Social y Periodista, Grupo de Investigación en Periodismo e Información, Universidad del Valle - Cali - Colombia. Doctoranda en Comunicación Social, Universidad Nacional de La Plata -Argentina, Becaria Doctoral Conicet.

${ }^{3}$ Periodista, Magíster en Ciencias de la Comunicación por la Universidad de La Frontera, Chile, y Doctor en Comunicación y Periodismo por la Universidad de Sevilla, España. Realizó su investigación posdoctoral en la Universidad de Oklahoma. Actualmente se desempeña como decano de la Facultad de Educación y Humanidades de la Universidad de la Frontera.

4 "En un comunicado, la Cancillería colombiana reconoció la responsabilidad del Estado en el asesinato del senador y ex integrante de la Unión Patriótica, Manuel Cepeda Vargas, ejecutado el 9 de agosto de 1994. En este caso, dos agentes del estado fueron condenados a 43 años de prisión: Hernando Medina Camacho y Justo Gil Zúñiga Labrador, suboficiales (r) del Ejército. Esta sentencia fue confirmada el 18 de enero de 2001 por el Tribunal Superior de Bogotá.http: / / www.semana.com/nacion/justicia/articulo/comienzan-audiencias-corte-interamericana-casomanuel-cepeda/112377-3

${ }^{5}$ El uso de este adjetivo hizo parte fundamental en el campo discursivo de Uribe como estrategia de la necesidad de la contrainsurgencia.

${ }^{6}$ Párrafo 83 de la intervención de Iván Cepeda.

${ }^{7}$ Intervención Iván Cepeda: https: / / www.youtube.com/watch?v= vsTyRSCOzBgIntervención Álvaro Uribe: https: / /www.youtube.com/watch?v=kSeJ56KR9nE

${ }^{8}$ Párrafo 11 de la intervención de Iván Cepeda.

${ }^{9}$ Párrafo 12 de la intervención de Iván Cepeda.

${ }^{10}$ Párrafo 18 de la intervención de Iván Cepeda.

11 "Jaime mi hermano, a raíz de que han asignado parientes que no tengo y no reconozco, lo único que he contestado y no repito, murió en 2001, casado con Astrid Vélez, tuvieron dos hijos, un joven profesional en materias ambientales y una niña que nació con parálisis cerebral, relación sentimental diferente que hubiera tenido mi hermano sería de su fuero íntimo y me es ajena; óigase bien, estuvo detenido en la tercera brigada, lo acusaron de clonación de un teléfono de Pablo Escobar y lo tuvieron que poner libre porque se comprobó que los días de la clonación mi hermano estaba hospitalizado por una cirugía de garganta que le impedía hablar, una cirugía por un cáncer en la garganta contra el cual el combatió mucho tiempo, que finalmente fue la causa de su muerte; agrónomo, promotor de las exportaciones de plátano, tomador de aguardiente, de costumbre comerciales absolutamente sanas; Santiago, mi hermano herido, junto con mi padre, cuando empieza mi aspiración a la gobernación de Antioquia empiezan los ataques contra mi hermano por la sola circunstancia de ser mi hermano» (Uribe) 
12 "Esos nexos no han sido negados, por lo menos algunos de esos nexos por el propio Álvaro Uribe. En un reportaje que dio al Meridiano de Córdoba, caracterizó de la siguiente forma su relación con el clan de los Ochoa Vélez. Mi papá y don Fabio Ochoa, eran amigos y rivales en ese medio, en el medio de la ganadería y de los caballos. Mis hermanos y yo participábamos en todas las ferias equinas, compitiendo contra sus hijos en los años 60 y 70 ; era un mundo sano, de fincas, caballos, tiple y aguardiente y poesía; así de esa manera sentimental, caracterizaba en el año 2002, el candidato de ese entonces a la presidencia Álvaro Uribe; pero, ya dijimos, no eran relaciones simplemente de tiple, de tertulia; no, eran relaciones comerciales; acabamos de ver, en una diapositiva anterior, la compra de una tierra por parte de Santiago Uribe, quien también aparece en esa fotografía que es ya muy conocida; con las hermanas Ochoa” (Cepeda).

13 “Álvaro Uribe Vélez fue nombrado director de la Aeronáutica entre los años 1980 y 1982, y tenía entre sus funciones, otorgar autorizaciones para aeródromos, hangares, matriculas de aeronaves, licencias para personal aeronáutico. Como se sabe, hay múltiples denuncias acerca de que el entonces director de la Aeronáutica, habría concedido licencias a personas relacionadas con el narcotráfico y con clanes que estaban operando tanto en Antioquía como en otras partes del país. Bueno nosotros nos tomamos el trabajo, en mi unidad legislativa, que ha hecho un trabajo extraordinario, de verificar algunos de esos casos. Repito, en la página web que señalé al comienzo está la información respectiva, pero voy a presentar aquí, algunos casos» (Cepeda).

14"A pesar de que, lástima que no esté aquí el director de la Aeronáutica, con ocasión del cuestionario que dirigimos, se nos dio la siguiente respuesta que está también en pantalla: Con ocasión de la presente preparación de la respuesta al Dr. Iván Cepeda con radicado número (...) sobre la relación de las licencias expedidas por la Autoridad Aeronáutica a partir del año 80 hasta el 82, se evidenció que en los libros en donde se encuentra consignada la información, faltan hojas y adicionalmente no se encontró libro de registros para varios tipos de licencia. Es decir, hay una sustracción de la información que hemos requerido; sin embargo, encontramos algunos hechos que son del mayor interés" (Cepeda).

15 “El primero de ellos, es que el entonces director de la Aeronáutica le concedió una licencia a su padre, al señor Alberto Uribe Sierra. Le concedió una licencia para el helicóptero que tiene la matrícula HK2704, que pertenecía a una compañía de la cual era integrante el señor Uribe Sierra, Aerofotos Amortegui Ltda. Pues bien, ese helicóptero apareció luego, y allí está el documento que sustenta, en la ciudadela del narcotráfico Tranquilandia. El senador Uribe ha dicho que, ellos, la familia Uribe, después de la muerte de su padre, hicieron una dación a la compañía; sin embargo, aquí tenemos el documento que muestra la fecha en que fue ese traspaso. Se produjo según lo dicho o lo autenticado en el documento, dos meses después de haberse producido este allanamiento, esta incautación” (Cepeda).

16 “Cuando en la gobernación de Antioquia fui de la junta del Banco Santander en Colombia, renuncié para aspirar a la presidencia de la república. En Medellín participé activamente en la junta de Mesacéy el gremio ganadero. Ahora me asignan otra junta. Dios premia la buena fe. Aquí me llegan las cartas donde yo digo que no acepto esa junta. Aquí están, señores senadores; yo no fui amigo de Luis Carlos Molina, ni hice negocios con él. Es que estas investigaciones a medias, y si lo que quieren con ese título de El Espectador hoy, es dejar suspicacias de una eventual participación mía en el asesinato de Guillermo Cano, llamemos las cosas por su nombre. Tienen que respetar. Yo he sido un hombre frentero y de combate. Tuve una gran amistad con Guillermo Cano y él conoció la honorabilidad de mi carrera pública. Entonces que no lo digan otros, ni empiecen con las suspicacias de los títulos, de los titulares, que, si la investigación está a medias, aquí está la carta de que yo no acepté participar en esa junta” (Uribe).

${ }^{17}$ Para acceder a la nota completa el lector se puede remitir a la url: http: / / noticiasunolaredindependiente.com/2014/09/21/noticias/no-recuerdo-la-amistad-con-miesposo-ana-maria-busquets/

${ }^{18}$ Párrafos 24 y 25 en la intervención de Álvaro Uribe.

19"Pasemos rápidamente a otra época, la de la Alcaldía de Medellín, bueno aquí de manera muy rápida lo voy a decir. Ha sido reconocido que la salida del muy fugaz Alcalde de Medellín en ese momento, Álvaro Uribe, puesto que estuvo en la Alcaldía de Medellín entre agosto y diciembre de 1982, se produjo a raíz de la preocupación que manifestó el entonces presidente de la 
república Belisario Betancur, con las siguientes palabras, al entonces Gobernador de Antioquía Álvaro Villegas Moreno, en un libro que ha sido reseñado por María Jimena Duzán, que es autobiográfico. El entonces Gobernador dice que el presidente de ese entonces Belisario Betancur lo llamó y le hizo en un tono airado la siguiente pregunta: ¿cómo es posible que tengamos en la Alcaldía de Medellín, a una persona de quien, me han dicho, tiene nexos con los narcotraficantes?" (Cepeda).

20 “Bueno, evidencia del escándalo que suscitó la salida de Álvaro Uribe de la Alcaldía de Medellín, también quedó registrada en la prensa, por ejemplo aquí tenemos un recorte de El Colombiano del 3 de Diciembre de 1982, en el que se dice que ha provocado un gran malestar en los círculos nacionales, el hecho de que el Alcalde participe en corridas taurinas, incluso en la calidad de torero, utilizando también, para llegar a esas corridas el helicóptero de la alcaldía y que en esas corridas de toros, estén también como rejoneadores los señores Ochoa y también, incluso el propio Pablo Escobar, como lo vamos a ver. Aquí tenemos una de esas corridas que suscitó el escándalo, la corrida de Nuquía del 28 de noviembre de 1982 en la que estuvieron presentes Fabio Ochoa y Álvaro Uribe Vélez" (Cepeda).

21 "Hacía consejos de seguridad diarios en la gobernación de Antioquia abiertos al público; consejos comunitarios los sábados y domingos en la gobernación de Antioquia. Pues los gobernadores no pueden. Y yo sí que cumplí eso... yo no sabía qué General iba llegar a una brigada u otra...los apoyaba a todos... a la Cuarta Brigada... su primer comandante fue el General Mora Rangel... puede dar testimonio de cómo fue esa época... hubo varios en la Cuarta Brigada; el ultimo el General Carlos Ospina, ya mencionado. Varios en la Brigada de Urabá; varios en la de Puerto Berrío. También nos tocaba en esa época dos divisiones, la de Santa Marta y la de Bucaramanga; creo que algunos Municipios de Antioquia les tocaba una Brigada de Montería.Y además había muchos comandos de policía; a todos los apoyé" (Uribe).

22 “Entonces ¿Qué pasó? Cuando yo salgo de la gobernación de Antioquia me dicen que me llama el general Herrera Berbel... mucho tiempo... oiga doctor Álvaro, defiéndanos, nos van a echar dos militares. Invitado por el General Herrera Berbel, acudí aquí al hotel Tequendama a un homenaje a los generales Millán y Del Rio. Allá hablaron personalidades muy importantes y siempre... y allí decía... había la consigna "estar en contra de guerrilla y de paramilitares" (Uribe).

${ }^{23}$ Nota periodística tomada de la página web del periódico ElTiempo: http: / /www.eltiempo.com/ politica/justicia/general-herrera-berbel-desmiente-a-lvaro-uribe/14555459

24 “Por allá dice un paramilitar, que se comunicaba con la Gobernación de Antioquia por Beeper. Allá no hubo. Yo no he conocido el Beeper. Jamás utilicé eso" (Uribe).

25 "Miren esto. Carlos Castaño, en su primera entrevista, cuando el país lo conoció, dada a Darío Arizmendi, para Caracol Televisión dijo que no me conocía, que estaban en desacuerdo conmigo, porque yo era guerrerista. Que habían votado y votarían por otras personas. Lo mismo le dijeron los paramilitares, incluido Carlos Castaño, a Luis Carlos Restrepo y al hoy Obispo de Cúcuta. Algunos compañeros míos visitaron el obispo y oyeron como él se ratifica en eso. Yo vi ese programa de televisión. Al otro día me llamó el Dr. Darío Arizmendi; me preguntó por mi amistad con Carlos Castaño, le dije, ya le contestaron a usted anoche" (Uribe).

26 “A mí me llama la atención que a veces en las entrevistas públicas, cuando se hace relación a este hecho, el hoy senador que tiene una memoria sorprendente; suele decir, bueno esa señora, digamos, tal vez simular que olvida su nombre, pero no, él tiene una relación de larga data con la señora López, no son personas desconocidas. Pero bueno, más allá de cualquier situación con relación a testimonios, con relación a afirmaciones, a denuncias, aquí en este mismo Senado, la senadora Claudia López hizo algunos días unas afirmaciones sobre las elecciones atípicas, cuando el Centro Democrático, la senadora Paloma Valencia, hizo un debate sobre la campaña electoral anterior y hablando de un método que ha aplicado para medir los resultados electorales, señaló que en las elecciones de 2002 y las elecciones de 2006, sin lugar a dudas, como nunca antes se había producido la victoria de un candidato en los municipios con influencia y presencia paramilitar» (Cepeda). 
27 “Mis campañas han sido austeras, mucho trabajo político, poco dinero, no ha habido derroche, ni ha faltado. Todo se ha declarado. Hablemos de doña Enilce López. Que hay una foto conmigo...las hay con miles. Ahí le pueden preguntar a la señora a ver si ha sido amiga mía. Cuando el señor Petro me acusó de que mi campaña había recibido unos dineros de ella, resulto que era verdad, pero no fue difícil esclarecerlo, porque estaban en la contabilidad de nuestra campaña. Lo que muestra la buena fe. Ese colombiano ejemplar Fabio Echeverri que manejó con rigor esas dos campañas, no permitía una sola trampa. Allí hubo una donación de personas de apuestas y apareció que uno de los contribuyentes de esa donación era una firma de doña Enilce López. Se declaró, lo reconocí como presidente ante el país" (Uribe).

28 "Entonces que obstaculicé investigaciones sobre para-política. Gracias a la Seguridad Democrática operó la parapolítica y no alcanzó a que operará la farc-política. Se crearon las condiciones y se cometieron muchas injusticias con congresistas. Con usted senador Velasco, se cometió una gran injusticia, como se cometió con otros. Le voy a decir en público algo que jamás me he atrevido a decirle en privado, porque no me gusta lavarme las manos. El gobierno fue totalmente respetuoso de esas decisiones, siempre que me preguntaron di mi concepto sobre usted. Usted me apoyó en una época, ha sido mi antagonista en muchas. Lo he respetado. Y con el respeto que usted ha sentido cuando lo he saludado o he cruzado dos palabras con usted, con ese mismo respeto lo he tratado en público" (Uribe).

29 "Y entonces ahora andan con el cuento del Hacker, para maltratar a un gran colombiano, a Oscar Iván Zuluaga y a mí. ¡Hombre! Como dije hace pocos días, el único hacker que yo necesito es un hacker en mi corazón, para que me ayude a meterme en el corazón de mis compatriotas... ique los quiero! Pero ese tema también está en la justicia” (Uribe).

${ }^{30} \mathrm{http}$ / / www.elespectador.com/noticias/judicial/condenan-10-anos-de-prision-al-hacker-andresfernando-s-articulo-554189

31 "Existen numerosas versiones del apoyo que dieron los paramilitares, a la primera campaña electoral. De ellas, quiero mostrar una que considero fundamental, que es la del señor Mancuso en una declaración de septiembre de 2012. ¿Sin sonido? Sin sonido. Yo no sé qué pasa aquí con la tecnología. En esa declaración el señor Mancuso dice que fue a visitarlo el Secretario de Gobierno de Álvaro Uribe Vélez, el señor Pedro Juan Moreno a expresarle la preocupación que tenía la campaña presidencial, porque estaban ocurriendo muchas acciones con “objetivo múltiple" es decir muchas masacres; y a pedirle al señor Mancuso y a los paramilitares que por favor le bajaran a las masacres; y que, a cambio, en un trueque razonable Uribe podría adelantar un proceso de paz con estos grupos. En esa misma declaración Mancuso señala que en el año 2001, después de esa visita, se hizo una cumbre de las Autodefensas, en la que se tomó la decisión, la doble decisión de, en primer lugar, bajar el número de "acciones de carácter múltiple” y, en segundo lugar, de respaldar en todos los frentes y bloques de esta organización criminal a Álvaro Uribe y sus candidatos" (Cepeda).

32 “Años después siendo gobernador me llamó el Ministro Carlos Medellín a decirme que mi voz, como gobernador y presidente de la federación de gobernadores, era muy importante para el congreso. Que apoyara el restablecimiento de la extradición; y lo hice; ahí está el testimonio de Carlos Medellín. Y la apliqué sin contemplaciones como presidente. Hay alrededor de 1.200 casos de extradición. Desmonté los paramilitares. No los conocí. A Salvatore Mancuso lo vi por mi vinculación a Montería de muchos años, en no más de dos o tres ocasiones públicas. Lo saludé y nunca conversé con él. Él dijo.Y lo conocí antes de ser paramilitar. Dijo que habían elegido el 33\% del congreso. En la misma declaración dijo que no habían participado de la elección presidencial. En plena campaña me llamó el padre de ru (silaba inentendible) y dijo: Mancuso le está diciendo a campesinos de Barrancas que voten por Uribe; salí públicamente a desautorizarlo. Lo que no hizo el presidente Santos ahora, apoyado por las Bacrim y las Farc, las mismas que la alianza funesta, la mezcla vitanda que ayer asesinó a los policías de Córdoba y que hace meses estaba recorriendo con fusiles, esa región; ordenando que había que votar por Santos. La misma mezcla maldita que hoy le ordena a los campesinos que no siembren palma, sino coca" (Uribe).

${ }^{33}$ http: / / www.semana.com/nacion/articulo/salvatore-mancuso-condenado-prision-en-estadosunidos/433137-3 


\section{Referencias}

Brunner, J. (1997). La educación, puerta de la cultura. Madrid: Visor.

Centro Nacional de Memoria Histórica. (2015). Una nación desplazada: informe nacional del desplazamiento forzado en Colombia. Bogotá: CNMH - UARIV.

Del Valle, C. (2009). Una Propuesta Metodológica para el Estudio del Significado de la Democracia en Estudiantes Universitarios. Anagramas Volumen 8, Universidad de Antioquia, Colombia.

Del Valle, C. - (2012). Ciudadanía, Tecnología y Cultura. Comunicación Serie Comunicología Latina.

Del Valle, C., \& Torres, E. (2014). Discurso y Poder:Aproximaciones Teóricas y Prácticas. Temuco: Universidad de La Frontera, Facultad de Educación, Ciencias Sociales y Humanas, Chile.

Estrada Álvarez, J., Fajardo Montaña, D., Giraldo Moreno, J., Molano Bravo, A., Moncayo Cruz, V. M., Vega Cantor, R., \& de Zubiría Samper, S. (2015). Conflicto Social y Rebelión Armada en Colombia. Bogotá D.C.: Gentes del Común.

Noscué, M. E., \& Angulo, A. (2011). Desplazamiento forzado, experiencias y medios de comunicación: experiencia de intervención social realizada en Colombia, Santiago de Cali, barrio Pizamos I. Santiago de Cali: Universidad del Valle, Escuela de Comunicación Social y Periodismo.

Pardo Abril, N. G. (2007). Cómo hacer análisis crítico del discurso: Una perspectiva latinoamericana. Bogotá D.C.: Universidad Nacional de Colombia, Facultad de Ciencias Humanas, Departamento de Lingüística, Instituto de Estudios en Comunicación y Cultura.

Ronderos, M. T. (2014). Guerras Recicladas. Una historia periodística del paramilitarismo en Colombia. Bogotá D.C. Aguilar.

Van Dijk, T. (1990). La Noticia como Discurso: Comprensión, Estructura, y Producción de la Información. Paidos Comunicación.

(1996). Análisis del Discurso Ideológico. Ámsterdam: Programa de Estudios del Discurso, Universidad de Ámsterdam, Holanda.

(2003). Ideología y análisis del discurso. Utopía y Praxis Latinoamericana [online]. vol.10, n.29

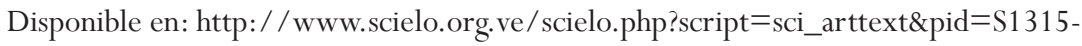

52162005000200002\&lng=es\&nrm=iso >. ISSN 1315-5216.

Recibido: marzo 2016/ Aprobado: mayo 2016

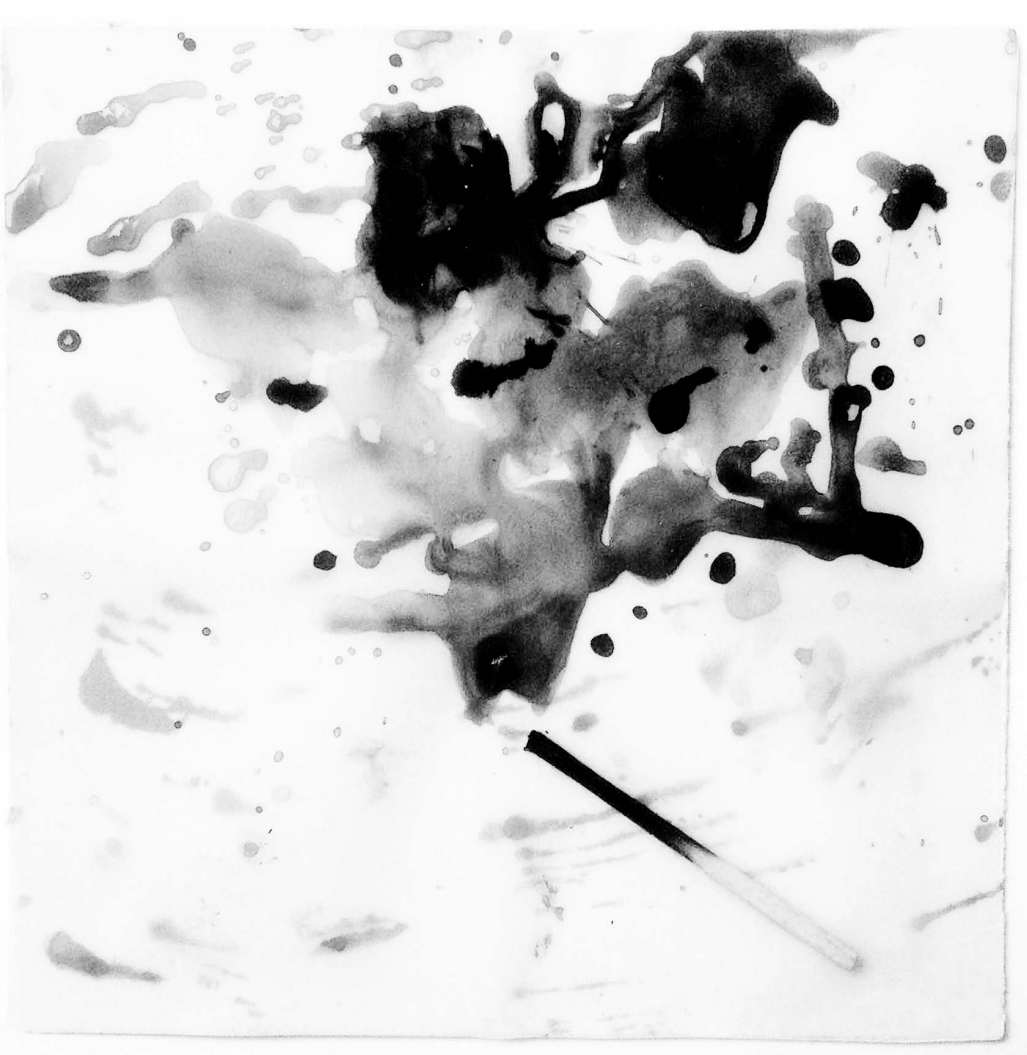

